\title{
NOX2 Protects against Prolonged Inflammation, Lung Injury, and Mortality following Systemic Insults
}

\author{
Laura C. Whitmore ${ }^{a-c}$ Brieanna M. Hilkin ${ }^{a, b}$ Kelli L. Goss ${ }^{a, b}$ Erin M. Wahle ${ }^{d}$ \\ Tarah T. Colaizy $^{a}$ Paola M. Boggiatto ${ }^{\text {e Steven M. Varga }}{ }^{\text {e }}$ Francis J. Miller $^{d}$ \\ Jessica G. Moreland ${ }^{\mathrm{a}-\mathrm{c}}$ \\ ${ }^{a}$ Department of Pediatrics, ${ }^{b}$ Inflammation Program, ${ }^{c}$ Molecular and Cellular Biology Program, and Departments of \\ dInternal Medicine and ${ }^{\mathrm{e}}$ Microbiology, The University of lowa and Veterans Affairs Medical Center, lowa City, lowa, USA
}

\section{Key Words}

Chronic granulomatous disease $\cdot$ gp9 $91^{\text {phox }} \cdot$ Inflammation .

NOX2 - Systemic inflammatory response syndrome

\begin{abstract}
The systemic inflammatory response syndrome (SIRS) is a clinical condition occurring in intensive care unit patients as a consequence of both infectious and noninfectious insults. The mechanisms underlying resolution of SIRS are not well characterized. NOX2 (NADPH oxidase 2)-derived reactive oxygen species are critical for killing of certain pathogens by polymorphonuclear leukocytes (PMN). Patients with chronic granulomatous disease who lack functional NOX2 are not only prone to serious infections, they also exhibit chronic inflammatory conditions, suggesting a local anti-inflammatory role for NOX2. We hypothesized that NOX2 is required for the resolution of sterile systemic inflammation. Using a murine model of sterile generalized inflammation, we observed dramatically increased mortality of gp $91^{\text {phox-/y }}$ (NOX2-deficient) as compared to wild-type (WT) mice. Both genotypes developed robust SIRS with hypothermia, hypotension, and leukopenia; however, WT mice recovered within $48 \mathrm{~h}$ whereas NOX2-deficient mice did not. Although both groups dis-
\end{abstract}

played rapid peritoneal PMN recruitment, the recruited NOX2-deficient PMN demonstrated an enhanced inflammatory phenotype. Moreover, NOX2-deficient mice exhibited a hemorrhagic inflammatory response in the lungs with rapid and persistent recruitment of neutrophils to the alveolar space, whereas WT mice had minimal lung pathology. Several proinflammatory cytokines remained elevated in NOX2deficient mice. The persistent inflammatory environment observed in NOX2-deficient mice resulted from continued peritoneal chemokine secretion and not delayed apoptosis of PMN. These data suggest a requirement for NOX2 in the resolution of systemic inflammation.

Copyright $\odot 2013$ S. Karger AG, Basel

\section{Introduction}

The systemic inflammatory response syndrome (SIRS) is a clinical condition that can be induced by either infectious or sterile insults, including sepsis, trauma, burns, and shock. The majority of patients admitted to intensive care units meet the criteria for SIRS [1]. While excessive proinflammatory responses can lead to early mortality, most patients develop a compensatory anti-inflammato-

\section{KARGER}

E-Mail karger@karger.com

www.karger.com/jin (c) 2013 S. Karger AG, Basel

1662-811X/13/0056-0565\$38.00/0
Dr. Jessica G. Moreland

Department of Pediatrics, The University of Iowa

200 Hawkins Drive

Iowa City, IA 52242 (USA)

E-Mail jessica-moreland@uiowa.edu 
ry response syndrome soon after the onset of SIRS in an attempt to restore immunological homeostasis [2]. Despite improved understanding of the pathogenesis of the compensatory anti-inflammatory response syndrome and SIRS, morbidity and mortality rates remain unacceptably high, demanding persistent investigation into basic mechanisms of inflammatory and immune balance.

Oxidant stress, or the pathologic effect of reactive oxygen species (ROS), has been extensively studied in the setting of sepsis and SIRS. The perception of increased ROS as a detrimental component of the host response led to several early clinical trials using antioxidant therapies to treat sepsis [3-5]. The mixed results of these trials suggested that the role of ROS in inflammatory responses is more complex than initially predicted. While several host enzymes can generate ROS, the essential role for NOX (NADPH oxidase)-derived ROS is evidenced by the human condition of chronic granulomatous disease (CGD). CGD is caused by a mutation in one of several subunits of the NOX2 complex. The most common form, X-linked CGD, is due to a mutation in the large gp91 ${ }^{\text {phox }}$ subunit. Phagocytes deficient in gp91 ${ }^{\text {phox }}$ lack superoxide production and are thereby unable to generate a respiratory burst. Thus, CGD patients are prone to frequent, severe infections by pathogens such as Staphylococcus aureus and Aspergillus [6]. However, patients with CGD also exhibit chronic inflammatory phenomena, such as granuloma formation and Crohn's-like colitis, in the absence of infection [7-9]. Studies in our laboratory using polymorphonuclear leukocytes (PMN) from CGD patients have provided an in vitro correlate for these clinical findings, with unstimulated CGD PMN displaying an activated or inflammatory phenotype characterized by high basal p38 MAPK phosphorylation and CD11b surface expression. A similar phenotype was observed by pharmacologic inhibition of NOX2 in unstimulated control PMN [10].

Recognizing that NOX2-derived ROS are required for microbial killing but also have a potential anti-inflammatory function, several investigators have utilized murine models to further elucidate these seemingly paradoxical roles of NOX2. Mice lacking gp91 ${ }^{\text {phox }}$ display infectious susceptibilities consistent with human CGD patients [11], and several studies utilizing these mice have delineated the requirement for NOX2 in host defense $[12,13]$. In addition to infections, mice deficient in gp91 ${ }^{\text {phox }}$ or p47 phox a cytosolic subunit of NOX2, display enhanced inflammation in a number of models. Zhang et al. [14] demonstrated that NOX2-deficient mice have enhanced inflammatory responses following intraperitoneal injection of LPS. This group subsequently demonstrated that intraperitoneal TNF- $\alpha$ led to increased inflammation of the lungs but not of other tissues in NOX2-deficient mice [15]. Segal et al. [16] showed that NOX2-deficient mice had exaggerated lung inflammation following localized delivery of LPS or zymosan, and experimental arthritis models revealed a critical anti-inflammatory role for NOX2 [17]. Considered in combination, the hyperinflammatory complications of human CGD and the numerous animal models have provided strong evidence that NOX2-derived ROS are necessary to limit localized sterile inflammatory processes.

In this study, we utilized a murine model of SIRS, zymosan-induced generalized inflammation (ZIGI), to specifically explore the role of NOX2 in the resolution of sterile systemic inflammation. Although both wild-type (WT) and NOX2-deficient mice developed a robust SIRS response, WT mice recovered quickly whereas NOX2deficient mice exhibited persistent SIRS and greatly increased early mortality. Pulmonary pathology was profoundly dependent on NOX2 with significant lung injury in NOX2-deficent mice and no detectable pathology in the lungs of WT mice. Overall, our results demonstrate that NOX2 is required for the normal resolution of sterile systemic inflammation.

\section{Materials and Methods}

\section{Materials}

Zymosan A from Sigma-Aldrich (St. Louis, Mo., USA) was boiled for $30 \mathrm{~min}$, thoroughly rinsed, and stored at $-20^{\circ} \mathrm{C}$. PMA was purchased from Sigma-Aldrich and ionomycin from EMD Biosciences (San Diego, Calif., USA). The FITC annexin V apoptosis detection kit II, BD GolgiStop ${ }^{\mathrm{TM}}$, mouse Foxp3 permeabilization concentrate, Alexa-Fluor ${ }^{\circledR} 488$ rat anti-mouse IL-17A, AlexaFluor 488 rat IgG1, PerCP-Cy ${ }^{\mathrm{TM}} 5.5$ rat anti-mouse CD4, and PE rat anti-mouse Ly-6G were purchased from BD Pharmingen (Franklin Lakes, N.J., USA). Rat $\operatorname{IgG}_{2 a}$, APC rat anti-mouse CXCR2, fluorescein rat anti-mouse CXCR4, and rat anti-mouse receptor for advanced glycation end products (RAGE) were from R\&D Systems (Minneapolis, Minn., USA). Rat anti-mouse CD11b was obtained from the Developmental Studies Hybridoma Bank at the University of Iowa (Iowa City, Iowa, USA) and PE hamster anti-mouse $\gamma \delta$ TCR and PE hamster IgG were purchased from eBioscience Inc. (San Diego, Calif., USA).

Animals

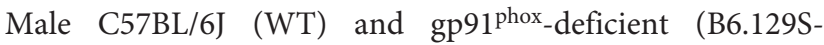
$\left.C y b b^{\text {tm1Din }} / \mathrm{J}\right)$ age-matched mice (11-15 weeks old) were used in all experiments. Mice were obtained from the Jackson Laboratory (Bar Harbor, Me., USA). The mice were kept in a barrier facility and had free access to standard rodent chow and water. All studies were performed according to protocols approved by the Institutional Animal Care and Use Committee at the University of Iowa. 


\section{Zymosan-Induced Generalized Inflammation}

Sterile systemic inflammation was induced using a previously described ZIGI model [18]. In pilot studies, WT mice were injected with intraperitoneal zymosan to determine the dose that caused $10 \%$ mortality $1-4$ days after injection. This dose $(0.7-0.8 \mathrm{mg} / \mathrm{g})$ was used for intraperitoneal injections in all subsequent experiments, except where otherwise specified. Both noninjected mice and mice injected with sterile saline were used as control groups. Prior to temperature and blood pressure (BP) measurements, mice were secured in animal nose cone holders. Core body temperature was measured with a monitoring thermometer (model TH-5) using a RET-3 probe (Physitemp Instruments Inc., Clifton, N.J., USA). The probe tip was coated with mineral oil and inserted to the length of the probe $(\sim 2 \mathrm{~cm})$. BP was measured using a Coda-2 noninvasive $\mathrm{BP}$ system according to the manufacturer's directions (Kent Scientific Corporation, Torrington, Conn., USA). Following five acclimation cycles, five cycles were recorded. The mean arterial pressure was used for statistics. After induction of SIRS, a subset of mice developed profound hypotension with BP below the detectable lower limit. For all mice with BP too low to be measureable, we assigned the lowest mean arterial BP value obtained for statistical analysis (44 mm Hg). Blood for complete blood counts was collected by cheek punch under isoflurane anesthesia into EDTA-coated tubes to prevent clotting, and data were collected with a Bayer ADVIA 120 hematology analyzer (Siemens AG, Erlangen, Germany) using the murine C57BL/6 algorithm. Mice were assessed for symptoms of systemic inflammation (lethargy, conjunctivitis, diarrhea, and ruffled fur) 6,24 , and $48 \mathrm{~h}$ after injection by a blinded observer. All symptoms were scored on a scale from 0 to $3(0=$ absent, $1=$ mild, $2=$ moderate, $3=$ severe $)$, and a total inflammation score was generated. In some experiments, mice were injected and observed for up to 21 days. In separate experiments, assessment for organ dysfunction was performed 6, 24, and $48 \mathrm{~h}$ after injection.

Assessment of Intraperitoneal Inflammation. Mice were sacrificed 6, 24, or $48 \mathrm{~h}$ after injection and assessed for intraperitoneal inflammation. Briefly, $2 \mathrm{ml}$ PBS were injected into the peritoneal cavity and then recovered. Recovered fluid was centrifuged at $500 \mathrm{~g}$ for $5 \mathrm{~min}$ and resuspended in HBSS without calcium and magnesium. Flow cytometry was used to analyze the influx and phenotype of PMN and the influx of specific T-lymphocyte subsets. Peritoneal lavage supernatant was used for a cytokine assay.

Evaluation of Lung Injury. Mice were sacrificed 6, 24, or $48 \mathrm{~h}$ after injection and the lungs were lavaged by intratracheal infusion of $3 \mathrm{ml}$ PBS followed by gravity drainage. Recovered fluid was centrifuged at $500 \mathrm{~g}$ for $5 \mathrm{~min}$, the pellet was resuspended in HBSS, and the total leukocyte number was counted with a hemocytometer. A cell differential was determined by creating a cytospin, fixing and staining the cells using a Hema 3 Stat Pack (Fisher Scientific, Pittsburgh, Pa., USA), and counting 100 leukocytes in two random fields.

\section{Bone Marrow Cell Isolation}

Control (noninjected and saline-injected) and ZIGI mice were euthanized 6, 24, or $48 \mathrm{~h}$ after injection, and the femurs were removed and stripped of tissue. After removal of the distal and proximal ends of the femur, cold HBSS with $1 \%$ dextrose and $0.1 \%$ BSA was used to flush the bone marrow cells from the shaft. Cells were pelleted at $500 \mathrm{~g}$ for $5 \mathrm{~min}$ and resuspended in HBSS before being analyzed by flow cytometry.

Prolonged Hyperinflammation of NOX2-Deficient Mice with SIRS

\section{T-Cell Subset Analysis}

Spleens and mediastinal lymph nodes were removed from noninjected mice and mice sacrificed 6,24 , or $48 \mathrm{~h}$ after injection. Spleens and lymph nodes were pulled apart using 25-gauge needles. The cells were passed through a $70-\mu \mathrm{m}$ cell strainer and suspended in RPMI 1640 with 10\% FBS. To assess recovered lymphocytes for IL-17A synthesis, splenocytes, lymph node cells, and a subset of the peritoneal cells were activated at a concentration of $2.5-5 \times 10^{6} / \mathrm{ml}$ by incubation in round-bottom 96 -well plates with $50 \mathrm{ng} / \mathrm{ml} \mathrm{PMA}, 500 \mathrm{ng} / \mathrm{ml}$ ionomycin, and BD GolgiStop at $37^{\circ} \mathrm{C}$ with $5 \% \mathrm{CO}_{2}$ for $3.5 \mathrm{~h}$. After the incubation, the plate was gently vortexed to resuspend the cells, with subsequent analysis using flow cytometry.

\section{Bacterial Culture of Peritoneal Fluid}

In a subset of experiments, $24 \mathrm{~h}$ after intraperitoneal zymosan injection, during recovery of the peritoneal lavage fluid, $100 \mu \mathrm{l}$ of the recovered fluid was plated on tryptic soy agar and blood agar plates to determine if bacterial contamination/infection of the peritoneum had occurred during inoculation of the animals with the sterile zymosan. Culture plates were placed in the incubator at $37^{\circ} \mathrm{C}$ and checked for growth on days $1-5$ after plating.

\section{Flow Cytometry}

Cells obtained by peritoneal lavage, bone marrow isolation, and lymph node dissection were fixed for $30 \mathrm{~min}$ in $4 \%$ paraformaldehyde on ice and then washed twice with cold PBS. Bone marrow cells and a subset of the peritoneal cells were blocked with PBS containing $4 \%$ NGS and $2 \%$ nonfat dry milk on ice for $20 \mathrm{~min}$. Primary antibodies, rat IgG2a, anti-CD11b, or anti-RAGE, were added for $1 \mathrm{~h}$ on ice. After washing, cells were resuspended in 1:1,000 FITC or PE-conjugated goat anti-mouse antibody (Jackson ImmunoResearch Laboratories Inc., West Grove, Pa., USA) for 30 min on ice in the dark followed by washing. Finally, cells were incubated with conjugated anti-Ly-6G and anti-CXCR2 or antiCXCR4 on ice for $1 \mathrm{~h}$ and washed before analysis.

After fixation, stimulated splenocytes, lymph node cells, and a subset of the peritoneal cells were resuspended in $2 \mathrm{ml}$ of $1 \times \mathrm{BD}$ Pharmingen mouse Foxp3 permeabilization buffer and incubated at $37^{\circ} \mathrm{C}$ for $1 \mathrm{~h}$. Cells were washed in PBS, centrifuged at $500 \mathrm{~g}$ for 5 min, then resuspended in PBS with 4\% NGS and 2\% nonfat dry milk and blocked on ice for $20 \mathrm{~min}$. Cells were stained with conjugated antibodies against CD4, IL-17A (or rat IgG), and $\gamma \delta$ TCR (or hamster IgG) in three color combinations for $1 \mathrm{~h}$ on ice and washed and resuspended in PBS prior to data collection.

For PMN apoptosis analysis, freshly isolated peritoneal cells were incubated with PE-conjugated anti-Ly-6G for $1 \mathrm{~h}$. Cells were then stained according to the annexin $\mathrm{V}$ kit manufacturer's instructions, substituting Hoechst for propidium iodide.

All data acquisition was performed on a BD LSR II (BD Biosciences, Sparks, Md., USA) in the Flow Cytometry Facility at the University of Iowa with $\geq 10,000$ events collected per analysis. In some experiments, prior to collection of 10,000 events, gating was directed to the lymphocyte population determined by FSC and SSC. In other experiments, the PMN (Ly-6G-positive) population was gated prior to event collection. Data were analyzed using FlowJo 7.6.4 software (Treestar, Ashland, Oreg., USA). 


\section{Histology}

Lungs, livers, and kidneys were collected for histological analysis from mice sacrificed 6, 24, or $48 \mathrm{~h}$ after injection and stored in $10 \%$ formalin at $4^{\circ} \mathrm{C}$. Tissues were sent to the Comparative Pathology Laboratory at the University of Iowa where they were embedded in paraffin, sectioned, stained with hematoxylin and eosin, and assessed by a veterinary pathologist blinded to treatment and genotype. Hemorrhage, thrombi, and the presence of PMN were scored on a scale from 0 to 3 ( $0=$ absent; $1=$ uncommon, detectable; 2 = multifocal, moderate; 3 = common, extensive, severe), and a total lung pathology score was generated.

\section{Plasma Collection and Multiplex Assays}

Mice were anesthetized with isoflurane and blood was collected via cheek puncture. Blood was placed in small tubes containing EDTA before centrifugation at 2,300 $\mathrm{g}$ for $5 \mathrm{~min}$. Plasma was removed and stored at $-80^{\circ} \mathrm{C}$.

Plasma samples ( $35 \mu \mathrm{l}$ diluted 1:3 with assay kit-provided sample buffer) from noninjected, saline-injected, and zymosan-injected mice were evaluated for cytokine content using a Bio-plex Pro $^{\mathrm{TM}}$ mouse cytokine 23-plex assay (Bio-Rad Laboratories, Hercules, Calif., USA) according to the manufacturer's instructions and analyzed on a Bio-Rad Bio-Plex (Luminex 200).

IL-6, KC, MCP-1, MIP-1 $\alpha$, and MIP-1 $\beta$ levels were measured in peritoneal lavage supernatant samples from zymosan-injected mice using a customized Bio-Plex mouse cytokine 5-plex express assay (Bio-Rad Laboratories) according to the manufacturer's instructions and analyzed on a Bio-Rad Bio-Plex (Luminex 200).

\section{Statistics}

The Kaplan-Meier (mortality) curve was evaluated for significance using a log-rank (Mantel-Cox) test. Temperature, BP, and heart rate data were analyzed by 2-way ANOVA with Bonferroni post tests using GraphPad PRISM 5.0 (GraphPad Software Inc., La Jolla, Calif., USA). Phenotypic analysis of peritoneal and bone marrow PMN was performed by ANOVA using SAS 9.3 (SAS Institute Inc., Cary, N.C., USA). For cytokine analyses, models were created using ANCOVA to test the main effects of genotype and time and their interaction on change in cytokine levels between baseline (noninjected) values and values 24 or 24-48 h after zymosan injection, adjusting for experiment to account for variation between cytokine plates run on different days. ANCOVA was also used to model absolute differences in cytokine levels 24 and $48 \mathrm{~h}$ after injection, adjusting for experiment. SAS 9.3 was used for all cytokine analyses. All other comparisons were made using unpaired Student's t tests using GraphPad PRISM 5.0. In all graphs, ${ }^{*} \mathrm{p}<0.05,{ }^{* *} \mathrm{p} \leq 0.01$, and ${ }^{* * *} \mathrm{p}<0.001$.

\section{Results}

\section{NOX2-Deficent Mice Exhibit High Early Mortality}

To investigate a potential role for NOX2 in resolving inflammation, we induced a sterile systemic inflammatory response in mice using a previously described ZIGI model [18]. In this model, intraperitoneal zymosan induces a triphasic illness during which mice become acutely ill (1-2 days after injection), followed by a brief period

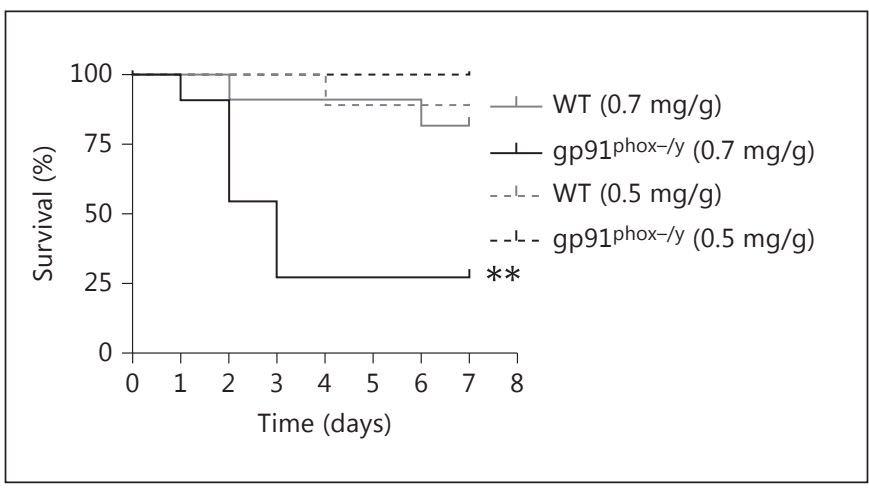

Fig. 1. NOX2-deficient mice exhibit increased mortality following zymosan injection. Kaplan-Meier curve displaying survival of WT and NOX2-deficient mice following zymosan injection. Injection of $0.7 \mathrm{mg} / \mathrm{g}$ i.p. zymosan elicited markedly increased mortality in NOX2-deficient mice $\left(\mathrm{n}=11\right.$ per genotype; $\left.{ }^{* *} \mathrm{p} \leq 0.01\right)$, whereas a $30 \%$ reduction in the zymosan dose elicited minimal mortality in either genotype $\left(n=1 / 9 \mathrm{WT}, 0 / 8 \mathrm{gp}^{\mathrm{phox}-/ \mathrm{y}}\right)$.

of apparent recovery (3-5 days after injection), followed by progression to multiple organ dysfunction and significant late mortality. In preliminary experiments, we tested a range of doses of intraperitoneal zymosan to determine the dose required to elicit $10 \%$ mortality in the WT mice (data not shown). We then injected WT and NOX2deficient mice with zymosan $(0.7 \mathrm{mg} / \mathrm{g})$ to compare the timing and extent of illness. Surprisingly, the NOX2-deficient mice exhibited significantly enhanced early mortality (73\%) compared to the WT mice (10\%). A 30\% reduction in the zymosan dose elicited minimal mortality in either genotype (fig. 1). No bacteria were recovered from the peritoneal cavity of either WT or NOX2-deficient mice. Mice that survived the acute illness also survived the later stages of the illness. Based on these results, we focused our subsequent studies on the initial $48 \mathrm{~h}$ after injection.

\section{WT and NOX2-Deficient Mice Develop SIRS in \\ Response to Zymosan and NOX2-Deficient Mice Exhibit Prolonged Hyperinflammation}

To evaluate parameters for the development of systemic inflammation in the mice, core body temperature, $\mathrm{BP}$, and heart rate were measured prior to zymosan injection and sequentially starting $6 \mathrm{~h}$ after injection. Both zymosan-injected WT and NOX2-deficient mice exhibited a significant decrease in core body temperature and mean arterial pressure $6 \mathrm{~h}$ after zymosan injection, indicative of an acute systemic inflammatory response (fig. 2). Mice 


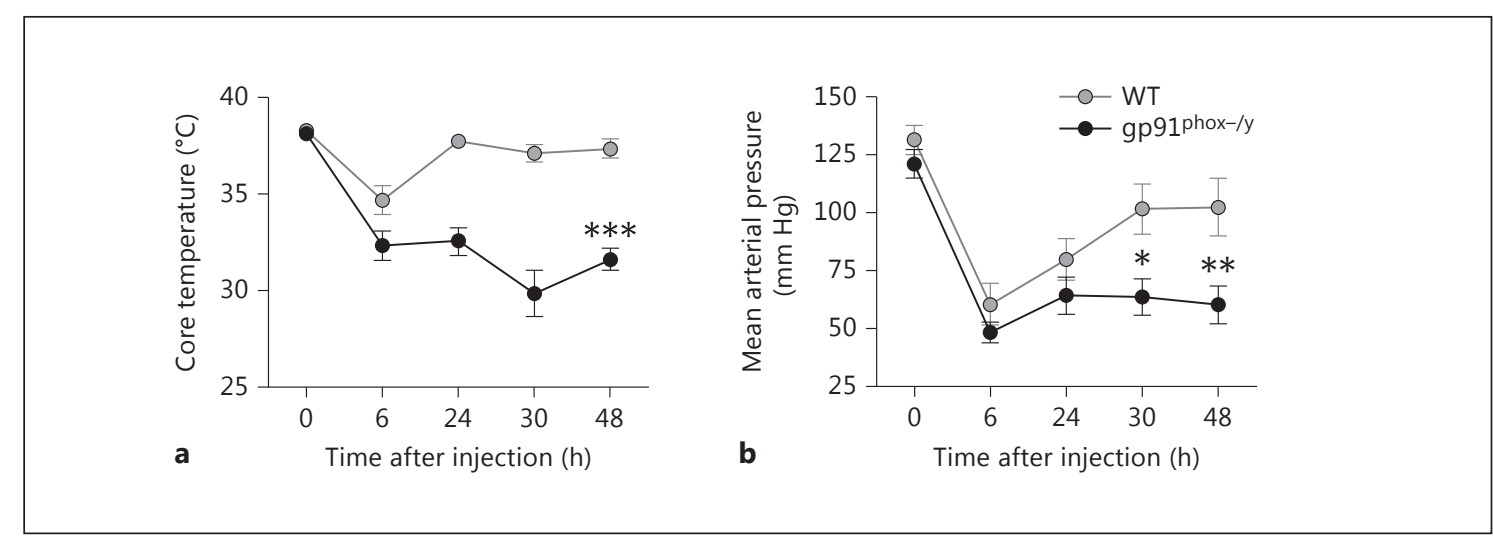

Fig. 2. NOX2-deficient mice develop prolonged hypothermia and hypotension following zymosan injection. Core body temperature (a) and BP (b) were measured at several time points following induction of SIRS by zymosan injection. a Mean core body temperature \pm SEM ( $n \geq 7$ animals per genotype per time point from 2 independent experiments). Two-way ANOVA with Bonferroni post tests revealed statistical significance between genotypes 6,24 , 30 , and $48 \mathrm{~h}$ after injection. ${ }^{* * *} \mathrm{p}<0.001$. b Mean arterial pressure \pm SEM ( $n \geq 10$ per genotype per time point from 3 independent experiments). Data were analyzed by two-way ANOVA with Bonferroni post tests. ${ }^{*} \mathrm{p}<0.05 ;{ }^{* *} \mathrm{p}<0.01$. from both groups also demonstrated severe hypotension, with many animals having BP below measureable levels $6 \mathrm{~h}$ after zymosan injection ( $\mathrm{n}=8 / 11 \mathrm{WT}$ and $\mathrm{n}=10 / 11$ NOX2-deficient mice). At $24-48 \mathrm{~h}$ after zymosan injection, the average temperature of the WT mice had returned to normal levels, while the NOX2-deficient mice displayed significant and persistent hypothermia (fig. 2a). Significant hypotension also persisted in the NOX2-deficient animals with 10/21 NOX2-deficient animals having $\mathrm{BP}$ values below the detection limit at 24 or $48 \mathrm{~h}$, compared to only 4/23 WT animals. The mean arterial pressure of the WT mice exhibited a return toward baseline values 30-48 h after injection, whereas the NOX2-deficient mice displayed significant ongoing hypotension (fig. 2b). Consistent with the prolonged hypotension observed in the NOX2-deficient mice, NOX2-deficient mice had a significantly higher heart rate $48 \mathrm{~h}$ after zymosan injection (data not shown).

As additional evidence for the development of SIRS, both genotypes demonstrated a profound decline in circulating WBC count $6 \mathrm{~h}$ after zymosan injection (fig. 3a). However, $48 \mathrm{~h}$ after injection, NOX2-deficient mice displayed significant persistent leukopenia compared to WT mice (fig. 3a) due to profound neutropenia, as evidenced both by neutrophil percentage (fig. $3 \mathrm{~b}$ ) as well as total neutrophil numbers $(\mathrm{p}=0.0071$; data not shown). The percentage of lymphocytes and monocytes remained similar between the genotypes (fig. 3c, d) though lymphocyte counts were significantly higher in the WT mice
$48 \mathrm{~h}$ after injection ( $\mathrm{p}=0.0256$; data not shown). There was no significant difference in hemoglobin levels between the genotypes though hemoglobin significantly dropped in both groups 6-24 h after injection (fig. 3e). Finally, platelet counts were significantly lower in the NOX2-deficient mice $48 \mathrm{~h}$ after zymosan injection (fig. 3f). These data provide strong evidence for the development of a SIRS phenotype in both groups of mice with prolongation of the proinflammatory response in the absence of NOX2.

WT and NOX2-deficient mice were also scored for lethargy, conjunctivitis, ruffled fur, and diarrhea, well-established symptoms of systemic inflammation in rodents [18], 6, 24, and $48 \mathrm{~h}$ after saline or zymosan injection. While there were no significant differences between the genotypes $6 \mathrm{~h}$ after zymosan injection (data not shown), the NOX2-deficient mice had a significantly greater total inflammation score at $24 \mathrm{~h}$ (fig. $4 \mathrm{a}$ ). The severity of individual symptoms varied between the genotypes with the NOX2-deficient mice displaying significantly greater lethargy and ruffled fur (fig. 4b-e). NOX2-deficient mice also exhibited significantly greater lethargy at $48 \mathrm{~h}(\mathrm{p}=$ $0.0025)$, but the total inflammation score was not different between the genotypes due to the progressive development of severe diarrhea in both genotypes (data not shown). Considered in combination with the hemodynamic and systemic cell counts, these data support our hypothesis that NOX2 is necessary to limit or resolve acute systemic inflammation. 
Fig. 3. NOX2-deficient mice have prolonged leukopenia and thrombocytopenia following induction of SIRS. Complete blood counts were performed on noninjected mice (time 0 ), and 6, 24, and $48 \mathrm{~h}$ after zymosan injection to evaluate WBC concentration (a), neutrophil (b), lymphocyte (c), and monocyte percentages (d), hemoglobin concentration (e), and platelet count (f). Means + SEM ( $\mathrm{n}=4$ mice per genotype at time $0, n \geq 6$ per genotype at subsequent time points from a minimum of 2 independent experiments). ${ }^{* *} \mathrm{p}<0.01$; $* * * \mathrm{p}<0.001$.
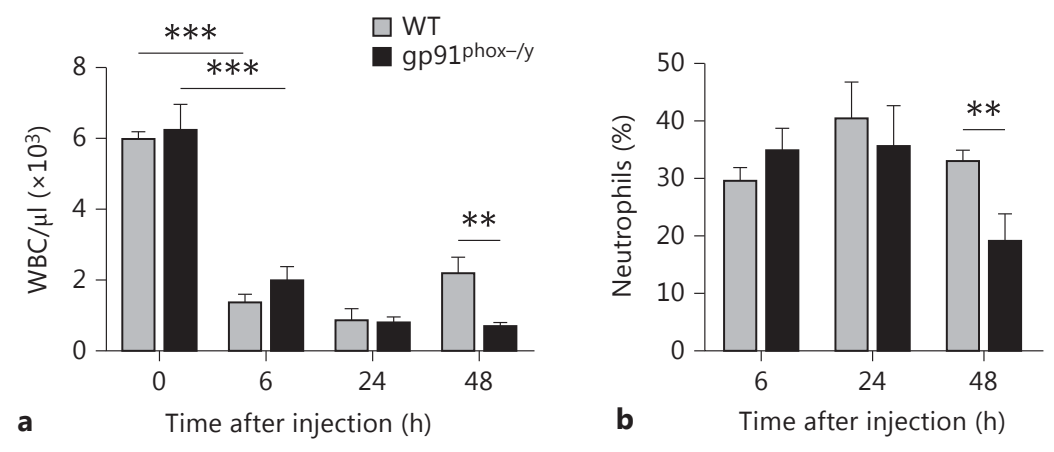

b

Time after injection $(h)$
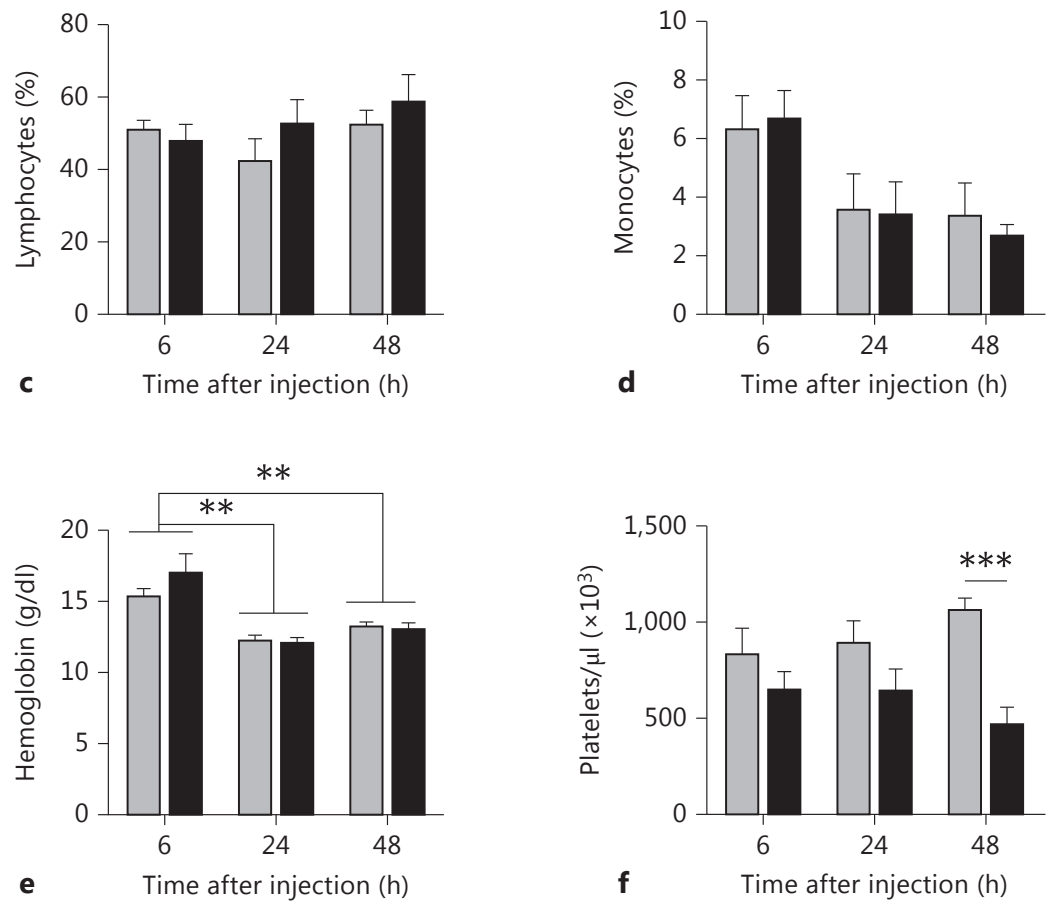

\section{NOX2-Deficient Mice Have Persistent PMN \\ Recruitment with Hyperinflammatory PMN \\ Phenotype}

In view of our data demonstrating persistent, severe systemic inflammation in NOX2-deficient mice injected with zymosan, we sought to quantify the local inflammatory response in the peritoneum. Both WT and NOX2deficient mice displayed robust $\mathrm{PMN}$ recruitment to the peritoneal cavity $6 \mathrm{~h}$ after zymosan injection with peritoneal lavage samples from WT and NOX2-deficient mice containing $63.3 \pm 12.5$ and $63.2 \pm 26.0 \% \mathrm{PMN}$, respectively (fig. 5a). At $24 \mathrm{~h}$ after zymosan injection, WT and
NOX2-deficient mice exhibited a similar decline in PMN percentages in the peritoneum with $46.2 \pm 17.8 \%$ in the WT and $31.9 \pm 20.0 \%$ in the NOX2-deficient samples. Notably, $48 \mathrm{~h}$ after injection, the peritoneal PMN count continued to decline significantly in WT mice, but NOX2deficient mice displayed persistence of PMN in the peritoneal cavity with no significant change between 24 and $48 \mathrm{~h}$ (fig. 5a), consistent with their increased clinical signs of inflammation. Based on the quantitative similarity of PMN recruitment at 6 and $24 \mathrm{~h}$, we evaluated the number of available PMN in the bone marrow of WT and NOX2deficient mice. In noninjected mice, there was no signifi- 

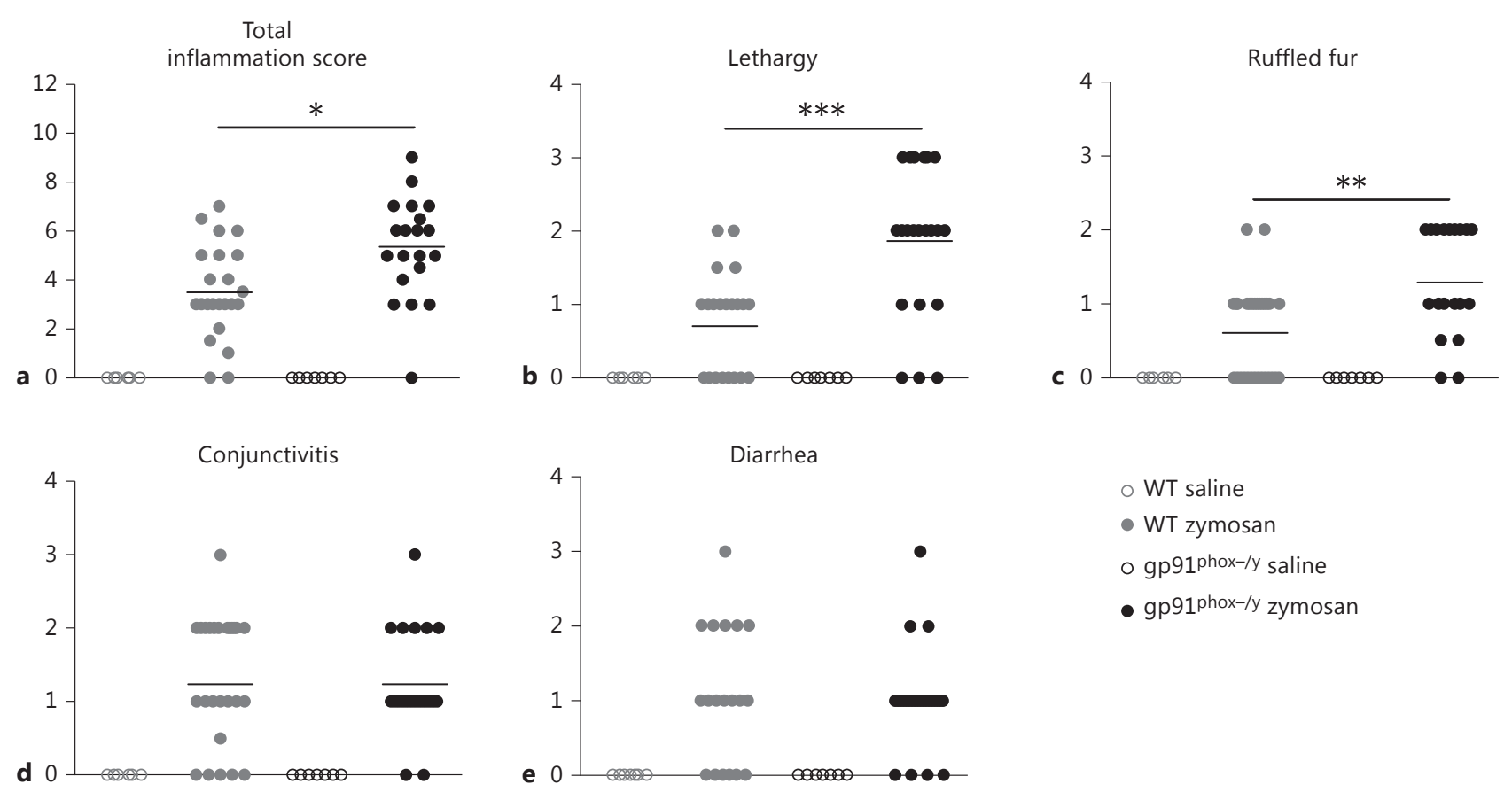

Fig. 4. NOX2-deficient mice display more severe symptoms of systemic inflammation. A total 24-hour inflammation score (a) was generated by scoring saline- and zymosan-injected mice for symptoms of systemic inflammation including lethargy (b), ruffled fur (c), conjunctivitis (d), and diarrhea (e) $24 \mathrm{~h}$ after injection. Each

dot represents a single mouse with means indicated by horizontal lines ( $\mathrm{n}=6 \mathrm{WT}$ saline, $\mathrm{n}=20 \mathrm{WT}$ zymosan, $\mathrm{n}=7 \mathrm{gp} 91^{\text {phox- }-\mathrm{y}}$ saline, and $\mathrm{n}=19 \mathrm{gp} 91^{\mathrm{phox}-/ \mathrm{y}}$ zymosan from 3 independent experiments). ${ }^{*} \mathrm{p}<0.05 ;{ }^{* *} \mathrm{p}<0.01$; $^{* * *} \mathrm{p}<0.001$. cant difference in bone marrow PMN percentages (fig. 5b). However, by $48 \mathrm{~h}$ after zymosan injection, the bone marrow analyses demonstrated significantly greater PMN stores in the WT as compared to the NOX2-deficient mice, suggesting that the decline in peritoneal inflammation in WT mice is not secondary to insufficient stores in the bone marrow, but more likely due to termination of the recruitment response.

Based on our previous human CGD data [10], we hypothesized that NOX2-deficient PMN have an altered inflammatory phenotype that would have implications on PMN function. We postulated that recruited PMNs would become 'primed' during the process of migration from the bone marrow to the peritoneal cavity with alterations in the levels of relevant cell surface markers. To quantitate this, we measured PMN cell surface levels of CXCR2, RAGE, CD11b, and CXCR4 on recruited peritoneal PMN and compared these levels to those measured on bone marrow PMNs from the same mouse (fold change; peritoneal/bone marrow). Although absolute levels of the chemokine receptor CXCR2 were not different between peritoneal PMN from WT compared to NOX2-deficient mice (fig. 5c), the fold change noted in peritoneal PMN/bone marrow PMN was significantly increased in NOX2-deficient PMN recruited to the peritoneum at 24 and $48 \mathrm{~h}$ in comparison to WT (fig. $5 \mathrm{~d}-\mathrm{e}$ ). Similarly, RAGE was upregulated on peritoneally recruited NOX2-deficient PMN over bone marrow PMN at $24 \mathrm{~h}$ (fig. $5 \mathrm{f}-\mathrm{h}$ ). Upregulation of CXCR2 and RAGE suggests increased capacity to generate amplification of inflammatory signaling by this cell population. The $\beta_{2^{-}}$ integrin, CD11b (Mac-1), is a well-described marker of $\mathrm{PMN}$ priming/pre-activation. Although peritoneal PMN from NOX2-deficient mice displayed significantly higher CD11b surface levels (fig. 5i), this was reflective of a baseline difference also noted in bone marrow PMNs (fig. 5j), rather than an increase during the recruitment process (fig. 5k). CXCR4 levels were used for comparison, as there 

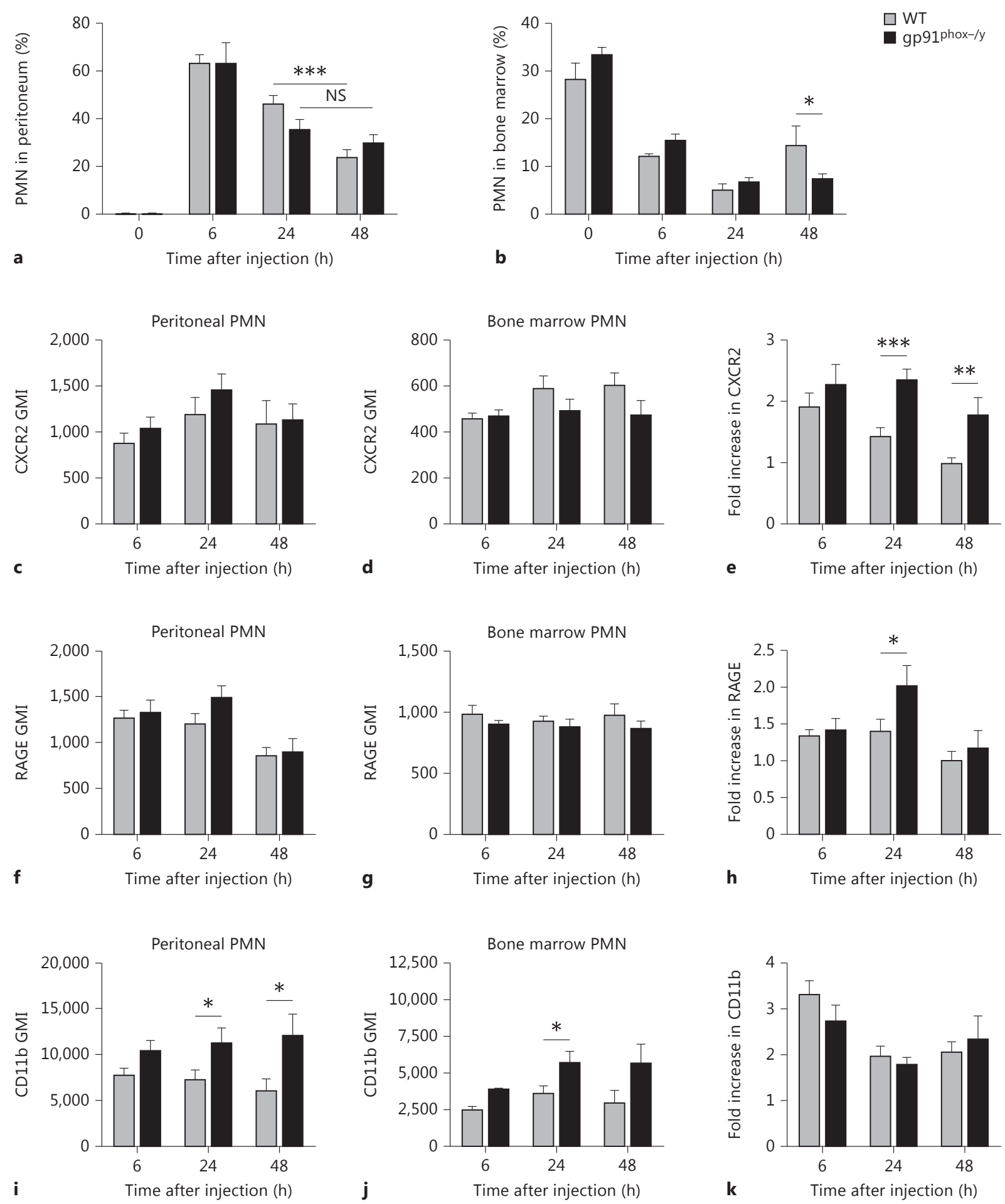

5 
is no reason to suspect alterations in surface levels under our experimental conditions. As predicted, no differences in CXCR4 surface expression levels were observed between genotypes on peritoneal or bone marrow PMN (data not shown). Taken together, our peritoneal PMN analyses suggest that there are several specific phenotypic alterations that occur on acutely recruited PMN in NOX2-deficient mice that might be predicted to enhance inflammatory signaling in the peritoneum.

\section{Deficiency of NOX2 Leads to Significant \\ Inflammatory Lung Pathology}

We next sought to investigate which organs are affected during the acute phase of the systemic inflammatory response. Bronchoalveolar lavage (BAL) samples were dramatically altered in NOX2-deficient mice with hemorrhagic, neutrophilic BAL fluid 6, 24, and $48 \mathrm{~h}$ after zymosan injection. Notably, BAL fluid from WT mice contained $<0.5 \%$ PMN at all time points while the NOX2deficient mice BAL fluid ranged from 25 to $31 \%$ PMN (fig. 6a). Additionally, the majority of the NOX2-deficient mice had grossly hemorrhagic BAL fluid both 24 $(\mathrm{n}=14 / 16)$ and $48 \mathrm{~h}$ after zymosan injection $(\mathrm{n}=16 / 18)$, whereas there was no evidence of hemorrhage in WT mice ( $\mathrm{n}=0 / 35,24$ and $48 \mathrm{~h}$ after zymosan injection). Total cell count was also greater in the absence of NOX2

Fig. 5. Differential peritoneal PMN recruitment and PMN activation states in WT and NOX2-deficient mice. Flow cytometry was used to determine the percentage of PMN (Ly-6G+ cells) in the peritoneum and bone marrow of WT and NOX2-deficient mice as well as measure PMN surface expression of CXCR2, RAGE, and CD11b. a PMN recruitment to the peritoneum of noninjected mice (time 0 ) and zymosan-injected mice 6, 24, and $48 \mathrm{~h}$ after injection. Means + SEM $(n=4$ noninjected and $n \geq 9$ zymosan-injected mice per genotype per time points from a minimum of 3 independent experiments). ${ }^{* * *} \mathrm{p}<0.0001$. NS $=$ Nonsignificant. b Percentage of PMN in the bone marrow of noninjected mice (time 0 ) and zymosan-injected mice 6, 24, and $48 \mathrm{~h}$ after injection. Means + SEM $(n=4$ noninjected and $n \geq 13$ zymosan-injected mice per genotype from a minimum of 3 independent experiments). ${ }^{*} \mathrm{p}<0.05$. $\mathbf{c}-\mathbf{j}$ The geometric mean index (GMI) of several inflammatory surface markers was determined by flow cytometry for gated PMN (Ly-6G+) populations isolated from the peritoneum and bone marrow of zymosan-injected mice 6, 24, and $48 \mathrm{~h}$ after injection. GMI of peritoneal PMN for CXCR2 (c), RAGE (f), and CD11b (i). GMI of bone marrow PMN for CXCR2 (d), RAGE (g), and CD11b (j). Fold increase (peritoneal PMN GMI/bone marrow PMN GMI) of CXCR2 (e), RAGE (h), and CD11b (k). Means + SEM ( $\mathrm{n} \geq 9$ per genotype per time point from a minimum of 3 independent experiments). ${ }^{*} \mathrm{p}<0.05$; ** $\mathrm{p}<0.01{ }^{* * *} \mathrm{p}<0.001$.

Prolonged Hyperinflammation of NOX2-Deficient Mice with SIRS compared to WT $\left(43.8 \times 10^{3}\right.$ vs. $18.3 \times 10^{3}$ cells; $\mathrm{p}=$ $0.0366)$ and $48 \mathrm{~h}$ after zymosan $\left(46.9 \times 10^{3}\right.$ vs. $33.0 \times 10^{3}$ cells; $\mathrm{p}=0.0523$ ). Noninjected and saline-injected animals of both genotypes had no evidence of PMN recruitment to the lungs or lung hemorrhage (data not shown).

By histopathology, the lungs of NOX2-deficient mice had significantly more thrombi, hemorrhage, and PMN infiltration than lungs of WT mice at $24 \mathrm{~h}$ (fig. 6b-g). Overall, the NOX2-deficient mice demonstrated a significantly higher total lung pathology score at $24 \mathrm{~h}$, which was further increased $48 \mathrm{~h}$ after zymosan injection (fig. 6h). Many mice that were included in the scoring for lung pathology underwent BAL first, thus potentially diminishing their lung pathology 'scores' under blinded conditions. NOX2 mice that underwent histopathological analysis without prior BAL were assigned higher pathology scores for both hemorrhage and inflammation, whereas there were no differences in WT mice, suggesting that the numeric differences between the genotypes in the lung pathology data (fig. $6 \mathrm{~b}-\mathrm{d}, \mathrm{h}$ ) may be blunted. These data indicate that NOX2 protects from acute lung injury during systemic inflammatory responses.

In addition to pulmonary pathology, small thrombi were present in the livers of a few zymosan-injected animals of each genotype and no kidney pathology was observed (data not shown).

\section{Pro- and Anti-Inflammatory Cytokines Are Elevated in the Plasma of NOX2-Deficient Mice}

The differences in the severity of local and systemic inflammation as well as survival between the WT and gp91 ${ }^{\text {phox-/y }}$ genotypes imply that the initial proinflammatory response is dysregulated in mice lacking functional NOX2. As cytokines are key orchestrators of systemic inflammatory responses, we measured the levels of 23 plasma cytokines using a multiplex assay. Following induction of SIRS, 15 of these cytokines were significantly increased in one or both genotypes $24 \mathrm{~h}$ after stimulation with zymosan ( $\mathrm{p}<0.001$, data not shown). We primarily focused on cytokines that were differentially increased based on genotype. Both WT and NOX2-deficient mice demonstrated a significant change in serum levels of MCP-1, G-CSF, RANTES, IL-17, MIP- $1 \beta$, IL-6, and IL-10 over the first $24 \mathrm{~h}$ after zymosan injection (fig. 7). Despite significant increases above baseline in both genotypes, MCP-1, G-CSF, RANTES, and IL-17 levels were significantly greater in NOX2-deficient animals at $24 \mathrm{~h}$ than in WT mice (fig. 7a-d). Notably, between 24 and $48 \mathrm{~h}$, there was a significant decline in several proinflammatory mediators in WT mice, including MCP-1, RANTES, IL-6, 


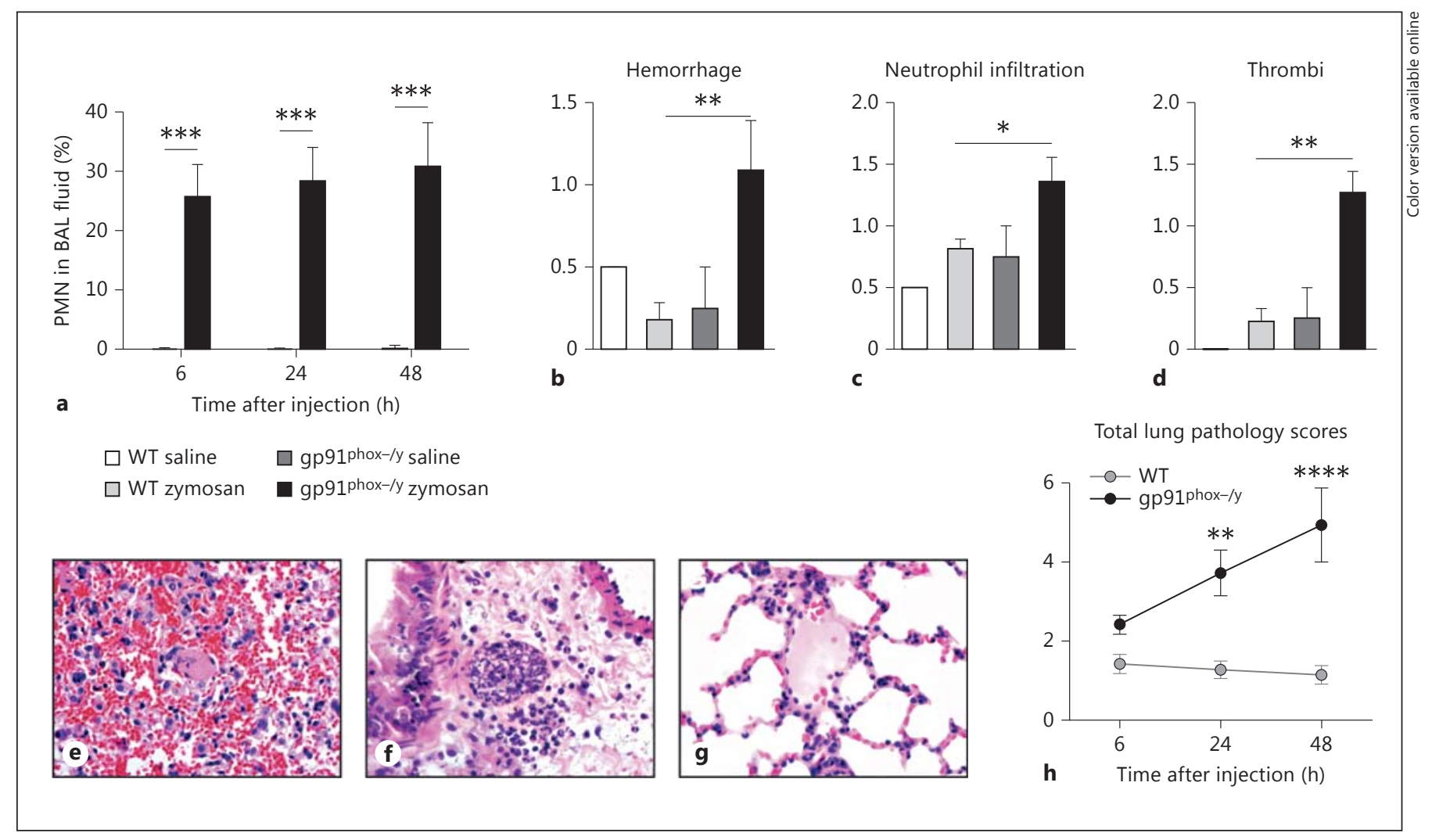

Fig. 6. NOX2-deficient mice have enhanced lung pathology compared to WT mice. a Percentage of PMN in the cells recovered from the BAL fluid of mice sacrificed 6, 24, and $48 \mathrm{~h}$ after zymosan injection. Hemorrhage (b), neutrophil infiltration (c), and thrombi (d) were scored in a blinded fashion 6, 24, and $48 \mathrm{~h}$ after zymosan injection ( $24 \mathrm{~h}$ data shown), representative images were taken $(\mathbf{e}-\mathbf{g})$, and total lung pathology scores were generated (h). a-d Means + SEM. ${ }^{*} \mathrm{p}<0.05 ;{ }^{* *} \mathrm{p}<0.01$; $^{* * *} \mathrm{p}<0.001$. a $\mathrm{n} \geq 7$

and IL-17, whereas NOX2-deficient mice displayed a downward trend but had persistent elevation of these mediators above baseline. RANTES, IL-17, and MIP- $1 \beta$ levels were significantly higher in NOX2-deficient mice at $48 \mathrm{~h}$ and remained above baseline (fig. 7c-e). IL-6 levels were dramatically elevated $24 \mathrm{~h}$ after zymosan injection in both genotypes, and NOX2-deficient mice had persistent elevation at $48 \mathrm{~h}$ (fig. 7f). Notably, TNF- $\alpha$ and IL- $1 \beta$ (not shown) were not elevated in either genotype 24 or $48 \mathrm{~h}$ after zymosan injection as compared with levels in the serum of noninjected mice. In addition, we observed that IL-10, an anti-inflammatory cytokine, was significantly elevated in NOX2-deficient mice compared to WT mice $24 \mathrm{~h}$ after zymosan injection (fig. $7 \mathrm{~g}$ ). We observed no significant differences between the two genotypes in baseline plasma cytokine levels (data not shown). per genotype per time point from 3 independent experiments. b-d $\mathrm{n}=2$ saline- and 11 zymosan-injected mice per genotype from 3 experiments. e-g Representative images (magnification: $\times 600$ ) of alveolar sections taken $24 \mathrm{~h}$ after zymosan injection. e Immune cell infiltration in a NOX2-deficient lung. $\mathbf{f}$ Hemorrhage and a thrombus in a NOX2-deficient lung. $\mathbf{g}$ WT lung (control). $\mathbf{h}$ Means $+\operatorname{SEM}(\mathrm{n}=6-11$ per genotype per time point from a minimum of 3 independent experiments). ${ }^{* *} \mathrm{p}<0.01 ;{ }^{* * * *} \mathrm{p}<0.0001$.

\section{NOX2-Deficient Mice Have Altered T-Cell \\ Populations Recruited to the Peritoneum}

The marked difference in IL-17 production between the NOX2-deficient mice and WT mice was striking and notable given recent publications reporting the expansion of Th17 cells in NOX2-deficient mice and patients with CGD $[19,20]$. Our cytokine assay revealed that NOX2-deficient mice injected with zymosan rapidly produced elevated levels of IL-17. As Th17 cells are key producers of IL-17, we hypothesized that there may be greater numbers of Th17 (CD4+IL-17A+) cells in the peritoneum or mediastinal lymph nodes of NOX2-deficient mice than WT mice after zymosan injection. Analysis of peritoneal cells demonstrated a significant increase in the percentage of $\mathrm{CD} 4 \mathrm{~T}$ cells found in the peritoneal lavage fluid recovered from WT mice compared to NOX2-defi- 
Fig. 7. Plasma levels of MCP-1 (a), G-CSF (b), RANTES (c), IL-17 (d), MIP-1 $\beta$ (e), IL-6 (f) and IL-10 (g) were persistently elevated in NOX2-deficient mice. Time $0=$ Noninjected. For MCP-1, G-CSF, and IL-6 some values were out of range for the multiplex ELISA. High out of range values were assigned the peak value within the measurable range for statistical comparison. Means + SEM ( $\mathrm{n} \geq 7$ noninjected and $\mathrm{n} \geq$ 9 zymosan-injected mice per genotype per time point from 3 independent experiments). ${ }^{*} \mathrm{p}<0.05 ;{ }^{* *} \mathrm{p}<0.01$.

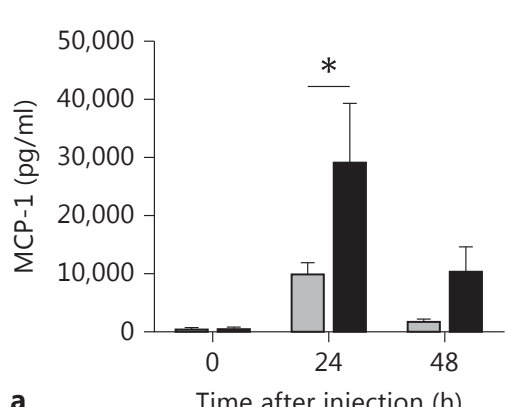

a
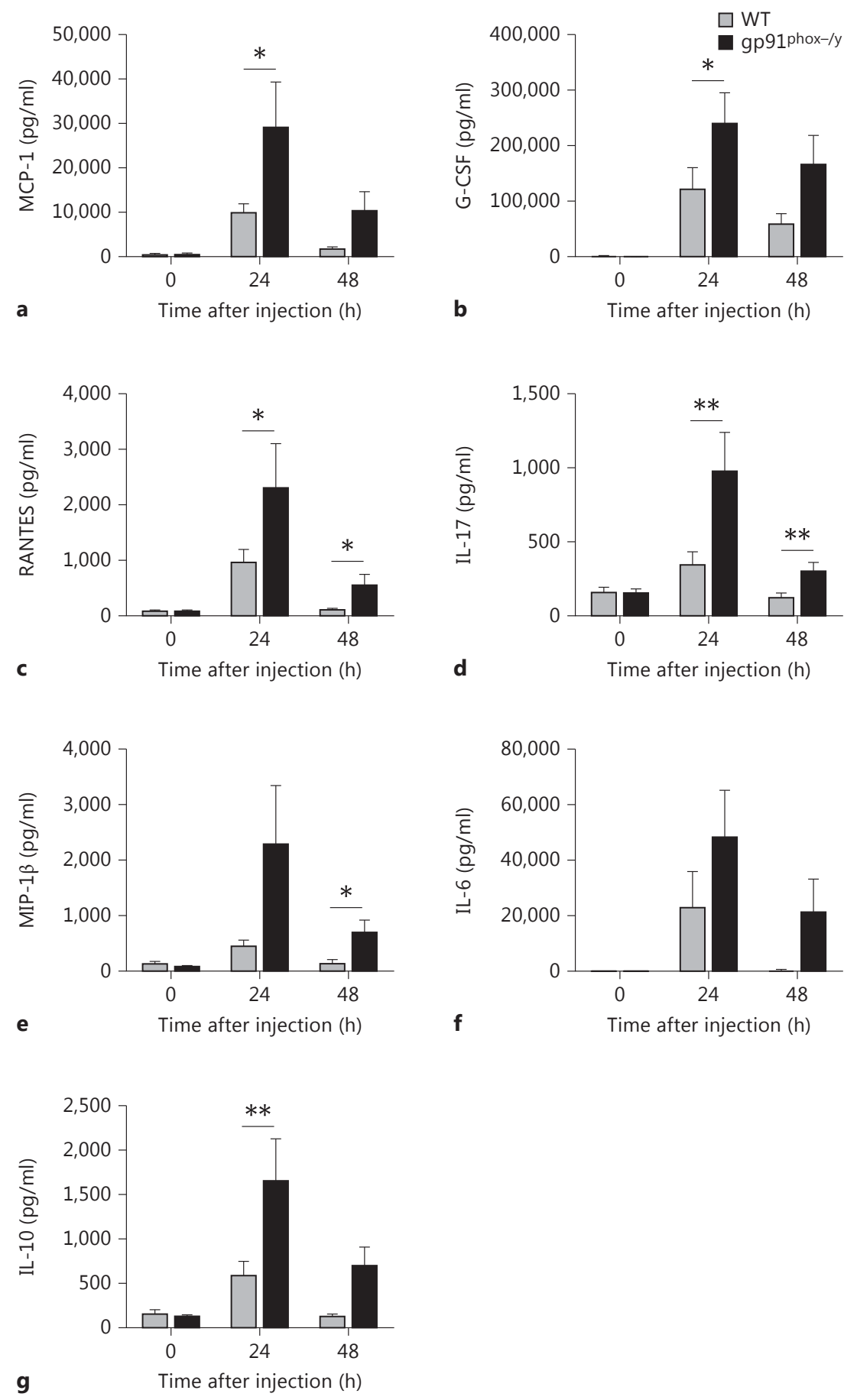

cient mice $24 \mathrm{~h}$ after injection (fig. 8a). However, NOX2deficient mice had a significantly higher frequency of peritoneal IL-17A+ CD4 T cells by intracellular staining (fig. $8 \mathrm{~b}$ ). In view of the rapid ( $<24 \mathrm{~h}$ ) rise in serum IL-17 levels, we also considered a potential role for $\gamma \delta$ T cells in
IL-17 production, as has been previously demonstrated in acute inflammatory responses [21,22]. Similar to our findings with the IL-17-producing CD4 T cells, NOX2deficient mice had a lower percentage of $\gamma \delta$ T cells than did WT mice (fig. 8c), but a slightly greater percentage of 

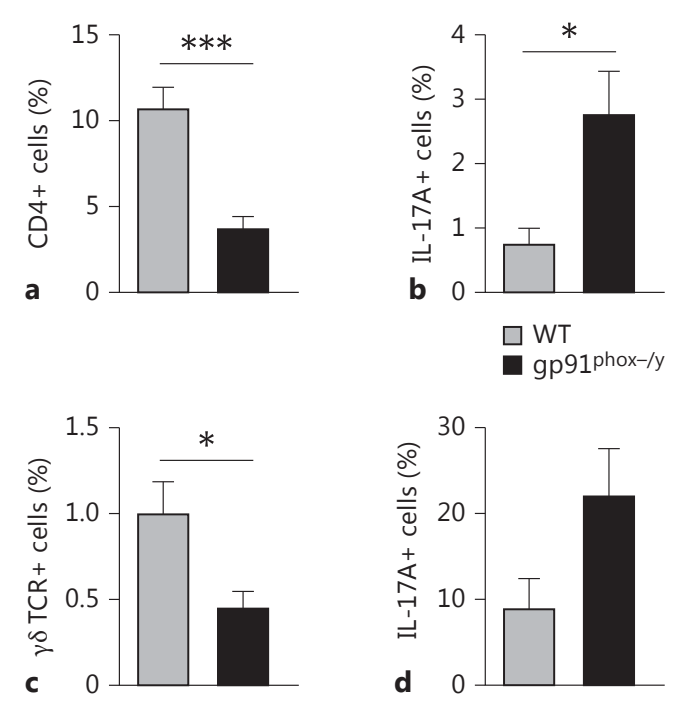

Fig. 8. Increased frequency of IL-17A-producing T-cell subsets in NOX2-deficient mice. Flow cytometry was used to identify CD4+, IL-17A+, and $\gamma \delta$ TCR+ cells in the peritoneum of zymosan-injected mice $24 \mathrm{~h}$ after injection. a Percentage of CD4+ cells. $\mathbf{b}$ CD4 T cells were gated and the percentage that was IL-17A+ was determined. c Percentage of $\gamma \delta$ TCR + cells. $\mathbf{d} \gamma \delta$ T cells were gated and the percentage that was IL-17A+ was determined. Means + SEM ( $\mathrm{n}=7$ per genotype from 2 independent experiments). ${ }^{*} \mathrm{p}<0.05$; $* * * \mathrm{p}<0.001$.

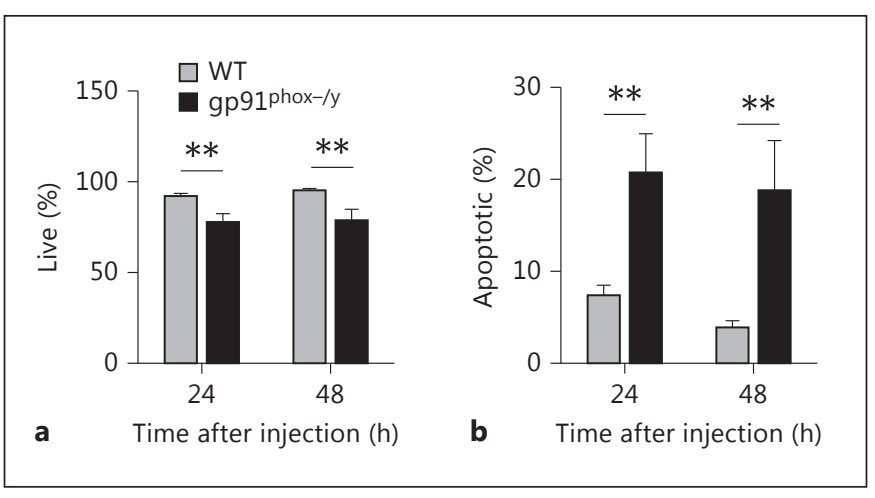

Fig. 9. Peritoneal PMN from NOX2-deficient mice display increased apoptosis. Flow cytometry was used to determine the percentage of PMN undergoing apoptosis in the peritoneum 24 and $48 \mathrm{~h}$ after SIRS induction. Apoptosis was evaluated by annexin $\mathrm{V}$ staining for exposed phosphatidylserine and Hoechst staining. Percentage of live (a; annexin V-negative, Hoechst-negative) and apoptotic (b; annexin V-positive) peritoneal PMN. Means + SEM ( $\mathrm{n} \geq 10$ per genotype per time point). ${ }^{*} \mathrm{p}<0.05$; ${ }^{* *} \mathrm{p}<0.01$; $* * * \mathrm{p}<0.001$. the NOX2-deficient cells were IL-17A positive (fig. 8d). We also analyzed $\gamma \delta$ and CD4 T-cell populations in the mediastinal lymph nodes which drain the peritoneal cavity. Both WT and NOX2-deficient mice had similar percentages of CD4 T cells, but the frequency of IL-17-producing cells was very low in both genotypes (data not shown). Overall numbers of $\gamma \delta$ T cells in the mediastinal nodes were very low and no differences were noted between the genotypes (data not shown). Splenocytes were also examined for IL-17A-producing T-cell subsets, but no differences were observed between genotypes (data not shown).

\section{NOX2-Deficient PMN Display Enhanced Apoptosis in} the Peritoneum

Despite the differences in IL-17-producing cells between the genotypes, the overall numbers were so low that it seemed unlikely to be the primary mechanism for increased mortality and inflammatory lung disease. CGD PMN have been previously described to have delayed apoptosis and thus increased inflammatory potential [23]. Based on these observations in humans, we explored alterations in PMN apoptosis in the NOX2-deficient mice as the mechanism for the prolonged, amplified inflammatory response. Remarkably, investigation of the peritoneally recruited PMN demonstrated a greater percentage of NOX2-deficient peritoneal PMN undergoing apoptosis as determined by phosphatidylserine staining than WT PMN 24 and $48 \mathrm{~h}$ after zymosan injection (fig. 9). Additionally, the NOX2-deficient mice had significantly higher absolute numbers of apoptotic PMN $48 \mathrm{~h}$ after injection ( $\mathrm{p}=0.01$; data not shown). These data imply that the persistent proinflammatory process was not due to failure or delay of PMN apoptosis. Additionally, these data suggest that dysregulated efferocytosis of apoptotic PMN by macrophages may be a mechanism involved in prolonged inflammation in NOX2-deficient mice.

\section{PMN Chemokines Are Persistently Elevated in the Peritoneum of NOX2-Deficient Mice}

In view of our apoptosis studies, we hypothesized that the NOX2-deficient mice would have ongoing PMN recruitment to the peritoneum. Based on our previous 23plex cytokine assay used to measure systemic cytokines, five potentially relevant inflammatory mediators were measured in the peritoneal lavage fluid of the mice, IL-6, KC, MCP-1, MIP- $1 \alpha$, and MIP-1 $\beta$ (fig. 10). IL-6, KC, and MCP-1 were elevated in both genotypes $6 \mathrm{~h}$ after injection. However, in the WT mice, these levels dropped sig- 


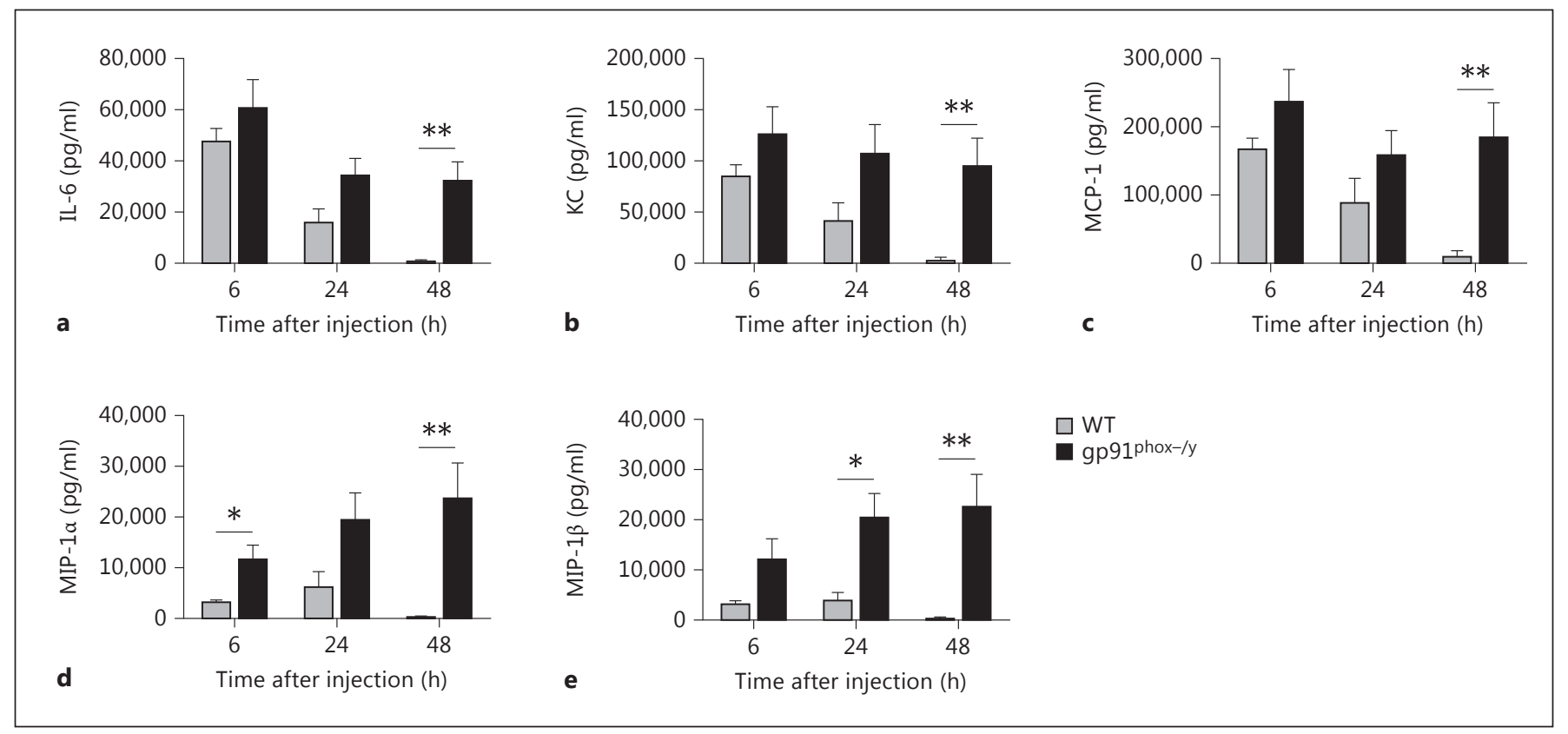

Fig. 10. Persistently elevated levels of inflammatory mediators in the peritoneum of NOX2-deficient mice. IL-6 $(\mathbf{a}), \mathrm{KC}(\mathbf{b}), \mathrm{MCP}-1$ (c), MIP-1 $\alpha(\mathbf{d})$, and MIP-1 $\beta$ (e) concentrations were measured in peritoneal fluid recovered from WT and NOX2-deficient mice 6, 24, and $48 \mathrm{~h}$ after SIRS induction. Means + SEM (n $\geq 6$ per genotype per time point from 3 independent experiments). ${ }^{*} \mathrm{p}<0.05 ;{ }^{* *} \mathrm{p}<0.01$.

nificantly at $24 \mathrm{~h}$ and were back to basal levels at $48 \mathrm{~h}$. In contrast, IL-6, KC, and MCP-1 remained significantly elevated in the NOX2-deficient PMN at all time points. The chemokines MIP- $1 \alpha$ and MIP- $1 \beta$ were slightly elevated in the WT mice 6 and $24 \mathrm{~h}$ after injection but had returned to baseline concentrations by $48 \mathrm{~h}$. However, in the NOX2-deficient mice, MIP- $1 \alpha$ and MIP- $1 \beta$ levels remained elevated at all time points with the highest levels at $48 \mathrm{~h}$. These data suggest that cytokines and chemokines are continuing to be secreted in the NOX2-deficient mice, resulting in continued PMN (and potentially monocyte) recruitment to sites of inflammation, including the peritoneum and the lung.

\section{Discussion}

In the setting of SIRS, innate immune cells encounter danger-associated molecular patterns and/or pathogenassociated molecular patterns, which activate these host cells and trigger responses including increased ROS generation and cytokine production. Increased generation of ROS has long been postulated to be detrimental, contributing to host tissue injury and the amplification of the inflammatory process [24]. However, accumulating data suggest that ROS have a dual role during inflammation. First, individuals with CGD, who lack superoxide production by the NADPH oxidase, exhibit a number of hyperinflammatory conditions, including granuloma formation and colitis $[8,9]$. Additionally, clinical trials using antioxidant therapies to treat sepsis did not protect against mortality $[4,5]$. Finally, several recent studies have demonstrated that NOX2-deficient mice have enhanced responses to local infectious and sterile inflammatory stimuli [14-16]. These lines of evidence suggest a potential anti-inflammatory role for ROS. The goal of this study was to determine whether NOX2-derived ROS have a role in limiting or resolving systemic inflammation.

The current investigation provides strong evidence for two primary novel findings. First, NOX2 has a critical anti-inflammatory function during sterile systemic inflammation, and, second, NOX2 specifically protects against the development of inflammatory lung disease during SIRS. In response to a generalized inflammatory stimulus, absence of NOX2 leads to profound dysregulation of the host response, including (1) marked abnormality of vital signs and circulating blood counts, (2) prolonged 
peritoneal PMN recruitment with an activated PMN phenotype, (3) a hemorrhagic, neutrophilic pulmonary inflammatory response, (4) impaired resolution of local and systemic inflammation, and (5) increased mortality. Our results are in contrast to two recent studies in which systemic NOX inhibitors were found to protect from lethality [25], and systemic oxidant scavengers limited mortality, peritonitis, and PMN infiltration of the lung and intestine after zymosan injection [26]. Importantly, both of these investigations employed global systemic reduction in ROS rather than targeted deletion of a single enzymatic source of ROS.

The most striking difference between the genotypes in our study was the inflammatory lung pathology evident in the NOX2-deficient mice. Hemorrhage, thrombus formation, and neutrophil recruitment were noted and are consistent with the development of inflammatory lung disease that is seen as a component of SIRS and is a well-described cause of morbidity and mortality in the intensive care unit patient [27]. Although genetic deficiency in NOX2 has been shown to enhance acute lung inflammation following intratracheal administration of LPS or zymosan $[14,16]$, to our knowledge, this is the first description of a specific role for NOX2 in the protection against inflammatory lung disease as a component of SIRS. Moreover, there was no evidence of lung pathology by BAL or histologic examination in the WT mice, whereas NOX2 mice displayed significant pathology at all time points studied, without any evidence of resolution of this process at $48 \mathrm{~h}$.

Unresolved or ongoing inflammation in the absence of NOX2 was not limited to the lungs. Although both genotypes had early, robust recruitment of neutrophils to the peritoneal cavity, WT mice displayed significant, continual resolution of peritoneal infiltrate through $48 \mathrm{~h}$, whereas neutrophilic infiltration persisted in the NOX2-deficient mice. There were also significant qualitative differences in the phenotype of the recruited PMN seen in WT and NOX2-deficient mice. We have previously demonstrated that human PMN with genetic deficiency in NOX2 (from CGD patients) or inactivation of NOX2 (PMN treated with diphenyleneiodonium) display evidence of an altered cell surface phenotype under resting conditions and impaired priming responses to endotoxin [10]. In the current study, NOX2-deficient PMN upregulate surface expression of CXCR2 and RAGE. RAGE is a pattern recognition receptor that recognizes a diverse spectrum of danger-associated molecular patterns [28]. Both increased RAGE and CXCR2 expression would elicit enhanced PMN responsiveness and perpetuation or augmentation of inflammation.
In light of strong evidence for significant enhancement of both local and systemic inflammation, we investigated the plasma levels of pro- and anti-inflammatory cytokines, key mediators of the inflammatory balance. Based on reports in the literature of the spontaneous development of inflammatory conditions in aging NOX2-deficient mice [19], we were surprised to find no differences in basal cytokine levels between the genotypes. Several chemokines were markedly increased in NOX2-deficient mice as compared to WT mice following zymosan injection. Among these, MIP-1a has been demonstrated to have a role in the development of SIRS following trauma [29]. We speculate that these increased levels may be secondary to hyperactivation of circulating monocytes/tissue macrophages in the absence of NOX2. A specific role for monocyte and macrophage NOX2 in SIRS responses is under investigation.

Notably, two cytokines were profoundly increased in the NOX2-deficient as compared to WT mice, IL-10 and the proinflammatory cytokine IL-17. IL-17A has many cellular targets and induces responses including proinflammatory cytokine production, which promotes PMN activation and recruitment [30]. While several cell types are now known to express IL-17A, two key producers are Th17 cells, a subset of CD 4 T cells, and $\gamma \delta$ T cells. Recently, studies in gp91 ${ }^{\text {phox-l- }}$ and $\mathrm{p} 47^{\text {phox-/- }}$ have revealed a skew toward enhanced Th17 cell differentiation contributing to inflammatory conditions such as arthritis [19] as well as enhanced $\gamma \delta$ T-cell activity [31]. We explored expansion of Th17 or $\gamma \delta$ T cells as the mechanism involved in the generation of the hyperinflammatory phenotype following SIRS. NOX2-deficient mice displayed a greater percentage of CD4 T cells that produced IL-17A than did WT mice, although total cell numbers were very low. The increased IL-17A levels were noted at $24 \mathrm{~h}$ raising the concern that mature Th17 cells could not be differentiated within this time interval; however, a study by Reynolds et al. [32] showed that stimulation of fully differentiated Th17 cells with certain TLR2 agonists alone elicited IL-17 production.

These subtle T-cell differences seemed unlikely to explain the vast difference in inflammatory pathology between the genotypes. Mechanisms of neutrophil cell death are now recognized to be critical to resolution of inflammation. Neutrophil apoptosis participates in the termination of acute inflammation by two distinct mechanisms: (1) reduced local tissue damage by PMN that undergo apoptosis rather than necrosis with leakage of contents, and (2) macrophage uptake of apoptotic PMN specifically signaling downregulation of the macrophage 
inflammatory program [33]. Moreover, CGD patients have been demonstrated to have delayed apoptosis under some conditions, suggesting a specific role for NOX2 in the control of neutrophil apoptosis [23, 34]. We postulated that the mechanism for the prolonged SIRS and acute lung injury pattern seen in our NOX2-deficient mice resulted from impaired or delayed apoptosis of peritoneally recruited PMN. However, our data not only failed to support this mechanism, but also demonstrated enhanced PMN apoptosis in the NOX2-deficient peritoneal PMN both 24 and $48 \mathrm{~h}$ after injection as compared to the WT.

Finally, our peritoneal cytokine data support the alternate mechanism of failure to terminate the primary proinflammatory response. Macrophage polarization is critical in shifting from the initial proinflammatory phase to a resolution phase [35], and a phenotype of 'resolution phase' macrophages regulated by cAMP has been described [36]. Our data suggest that, in the absence of NOX2, the proinflammatory signaling persists with ongoing generation of MCP-1, MIP- $1 \alpha$, and MIP- $1 \beta$, likely generated by M1 macrophages or monocytes in the peritoneal cavity. Each of these chemokines has proinflammatory activity, with recent evidence of neutrophil chemotactic properties [37, 38]. Moreover, altered macrophage programming has been demonstrated in NOX2-deficient mice and implicated in dysregulated neutrophil clearance/efferocytosis [39].

In conclusion, this study reveals a novel role for NOX2 in the resolution of systemic inflammatory responses, and, specifically, in limiting pulmonary inflammation during SIRS. The sterile inflammatory stimulus delivered in our model elicited local PMN infiltration and systemic cytokine elevation in WT mice, but inflammation was readily suppressed with short-term return to homeostasis and no end-organ failure. Conversely, in the absence of
NOX2, the systemic progression of the acute inflammatory phase was markedly augmented with rapid development of distant organ involvement and damage. These data do not provide direct evidence as to which NOX2expressing cell(s) is/are responsible for this dysregulated inflammation, but our laboratory is actively investigating this question. Specifically, failure to terminate or reprogram the macrophage/monocyte inflammatory response is suggested and is currently being explored. In the clinical setting of SIRS, the majority of patients mount compensatory anti-inflammatory responses soon after the onset of SIRS, curbing inflammation and initiating a return to immunological homeostasis [2]. Our data indicate that NOX2-deficient mice are unable to curb the proinflammatory response, suggesting that NOX2-derived ROS may have an inhibitory function, dampening SIRS or, alternatively, that these ROS are necessary for the initiation of a compensatory anti-inflammatory response syndrome.

\section{Acknowledgments}

This work was supported by NIH grant R01 AI073872 to J.G.M., a Carver Foundation Award to J.G.M and F.J.M, and by the Office of Research and Development, Department of Veterans Affairs to F.J.M. We acknowledge the Comparative Pathology Laboratory at the University of Iowa for their assistance with tissue processing and histopathologic examination. Complete blood counts were obtained in the David Motto Laboratory at the University of Iowa. The flow-cytometric data presented herein were obtained at the Flow Cytometry Facility, which is a Carver College of Medicine Core Research Facilities/Holden Comprehensive Cancer Center Core Laboratory at the University of Iowa. The CD11b murine antibody developed by TA Springer was obtained from the Developmental Studies Hybridoma Bank developed under the auspices of the NICHD and maintained in the University of Iowa, Department of Biology, Iowa City, Iowa, USA.

\section{References}

1 Robertson CM, Coopersmith CM: The systemic inflammatory response syndrome. Microbes Infect 2006;8:1382-1389.

2 Adib-Conquy M, Cavaillon JM: Compensatory anti-inflammatory response syndrome. Thromb Haemost 2009; 101:36-47.

-3 Galley HF, Howdle PD, Walker BE, Webster NR: The effects of intravenous antioxidants in patients with septic shock. Free Radic Biol Med 1997;23:768-774.
-4 Spies CD, Reinhart K, Witt I, Meier-Hellmann A, Hannemann L, Bredle DL, Schaffartzik W: Influence of N-acetylcysteine on indirect indicators of tissue oxygenation in septic shock patients: results from a prospective, randomized, double-blind study. Crit Care Med 1994;22:1738-1746.

5 Peake SL, Moran JL, Leppard PI: N-acetyl-Lcysteine depresses cardiac performance in patients with septic shock. Crit Care Med 1996; 24:1302-1310.
6 Holland SM: Chronic granulomatous disease. Clin Rev Allergy Immunol 2010;38:3-10.

7 Winkelstein JA, Marino MC, Johnston RB Jr, Boyle J, Curnutte J, Gallin JI, Malech HL, Holland SM, Ochs H, Quie P, Buckley RH, Foster $\mathrm{CB}$, Chanock SJ, Dickler H: Chronic granulomatous disease. Report on a national registry of 368 patients. Medicine (Baltimore) 2000; 79:155-169.
Prolonged Hyperinflammation of NOX2-Deficient Mice with SIRS
J Innate Immun 2013;5:565-580 DOI: $10.1159 / 000347212$ 
8 Rieber N, Hector A, Kuijpers T, Roos D, Hartl D: Current concepts of hyperinflammation in chronic granulomatous disease. Clin Dev Immunol 2012;2012:252460.

-9 Schappi MG, Jaquet V, Belli DC, Krause KH: Hyperinflammation in chronic granulomatous disease and anti-inflammatory role of the phagocyte NADPH oxidase. Semin Immunopathol 2008;30:255-271.

10 Moreland JG, Davis AP, Matsuda JJ, Hook JS, Bailey G, Nauseef WM, Lamb FS: Endotoxin priming of neutrophils requires NADPH oxidase-generated oxidants and is regulated by the anion transporter ClC-3. J Biol Chem 2007;282:33958-33967.

11 Pollock JD, Williams DA, Gifford MA, Li LL, Du X, Fisherman J, Orkin SH, Doerschuk CM, Dinauer MC: Mouse model of X-linked chronic granulomatous disease, an inherited defect in phagocyte superoxide production. Nat Genet 1995;9:202-209.

12 Mastroeni P, Vazquez-Torres A, Fang FC, Xu Y, Khan S, Hormaeche CE, Dougan G: Antimicrobial actions of the NADPH phagocyte oxidase and inducible nitric oxide synthase in experimental salmonellosis. II. Effects on microbial proliferation and host survival in vivo. J Exp Med 2000;192:237-248.

13 Aratani Y, Kura F, Watanabe H, Akagawa H, Takano Y, Suzuki K, Dinauer MC, Maeda N, Koyama H: Critical role of myeloperoxidase and nicotinamide adenine dinucleotide phosphate-oxidase in high-burden systemic infection of mice with Candida albicans. J Infect Dis 2002;185:1833-1837.

14 Zhang WJ, Wei H, Frei B: Genetic deficiency of NADPH oxidase does not diminish, but rather enhances, LPS-induced acute inflammatory responses in vivo. Free Radic Biol Med 2009;46:791-798.

15 Zhang WJ, Wei H, Tien YT, Frei B: Genetic ablation of phagocytic NADPH oxidase in mice limits TNF $\alpha$-induced inflammation in the lungs but not other tissues. Free Radic Biol Med 2011;50:1517-1525.

-16 Segal BH, Han W, Bushey JJ, Joo M, Bhatti Z, Feminella J, Dennis CG, Vethanayagam RR, Yull FE, Capitano M, Wallace PK, Minderman H, Christman JW, Sporn MB, Chan J, Vinh DC, Holland SM, Romani LR, Gaffen SL, Freeman ML, Blackwell TS: NADPH oxidase limits innate immune responses in the lungs in mice. PLoS One 2010;5:e9631.
17 van de Loo FA, Bennink MB, Arntz OJ, Smeets RL, Lubberts E, Joosten LA, van Lent PL, Coenen-de Roo CJ, Cuzzocrea S, Segal $\mathrm{BH}$, Holland SM, van den Berg WB: Deficiency of NADPH oxidase components p47phox and gp91phox caused granulomatous synovitis and increased connective tissue destruc tion in experimental arthritis models. Am J Pathol 2003;163:1525-1537.

18 Volman TJ, Hendriks T, Goris RJ: Zymosaninduced generalized inflammation: experimental studies into mechanisms leading to multiple organ dysfunction syndrome. Shock 2005;23:291-297.

$>19$ Lee K, Won HY, Bae MA, Hong JH, Hwang ES: Spontaneous and aging-dependent development of arthritis in NADPH oxidase 2 deficiency through altered differentiation of CD11b+ and Th/Treg cells. Proc Natl Acad Sci USA 2011;108:9548-9553.

20 Horvath R, Rozkova D, Lastovicka J, Polouckova A, Sedlacek P, Sediva A, Spisek R: Expansion of T helper type 17 lymphocytes in patients with chronic granulomatous disease. Clin Exp Immunol 2011;166:26-33.

21 Martin B, Hirota K, Cua DJ, Stockinger B, Veldhoen M: Interleukin-17-producing $\gamma \delta \mathrm{T}$ cells selectively expand in response to pathogen products and environmental signals. Immunity 2009;31:321-330.

22 Matsushima A, Ogura H, Fujita K, Koh T, Tanaka H, Sumi Y, Yoshiya K, Hosotsubo H, Kuwagata Y, Shimazu T, Sugimoto H: Early activation of $\gamma \delta \mathrm{T}$ lymphocytes in patients with severe systemic inflammatory response syndrome. Shock 2004;22:11-15.

23 Luo HR, Loison F: Constitutive neutrophil apoptosis: mechanisms and regulation. Am J Hematol 2008;83:288-295.

24 Crimi E, Sica V, Williams-Ignarro S, Zhang $\mathrm{H}$, Slutsky AS, Ignarro LJ, Napoli C: The role of oxidative stress in adult critical care. Free Radic Biol Med 2006;40:398-406.

25 Impellizzeri D, Mazzon E, Di Paola R, Paterniti I, Bramanti P, Cuzzocrea S: Effect of NADPH-oxidase inhibitors in the experimental model of zymosan-induced shock in mice. Free Radic Res 2011;45:820-834.

26 Cuzzocrea S, Costantino G, Mazzon E, Caputi AP: Protective effect of N-acetylcysteine on multiple organ failure induced by zymosan in the rat. Crit Care Med 1999;27:1524-1532.

27 Leaver SK, Evans TW: Acute respiratory distress syndrome. BMJ 2007;335:389-394.

$>28$ Bianchi ME: DAMPS, PAMPS and alarmins: all we need to know about danger. J Leukoc Biol 2007;81:1-5.
29 Hsieh CH, Frink M, Hsieh YC, Kan WH, Hsu JT, Schwacha MG, Choudhry MA, Chaudry IH: The role of MIP-1 alpha in the development of systemic inflammatory response and organ injury following trauma hemorrhage. J Immunol 2008;181:2806-2812.

30 Iwakura Y, Ishigame H, Saijo S, Nakae S: Functional specialization of interleukin-17 family members. Immunity 2011;34:149-162.

-31 Romani L, Fallarino F, De Luca A, Montagnoli C, D’Angelo C, Zelante T, Vacca C, Bistoni F, Fioretti MC, Grohmann U, Segal BH, Puccetti P: Defective tryptophan catabolism underlies inflammation in mouse chronic granulomatous disease. Nature 2008;451: 211-215.

32 Reynolds JM, Pappu BP, Peng J, Martinez GJ, Zhang Y, Chung Y, Ma L, Yang XO, Nurieva RI, Tian Q, Dong C: Toll-like receptor 2 signaling in CD4(+) $\mathrm{T}$ lymphocytes promotes $\mathrm{T}$ helper 17 responses and regulates the pathogenesis of autoimmune disease. Immunity 2010;32:692-702.

33 Duffin R, Leitch AE, Fox S, Haslett C, Rossi AG: Targeting granulocyte apoptosis: mechanisms, models, and therapies. Immunol Rev 2010;236:28-40.

34 Rieber N, Hector A, Kuijpers T, Roos D, Hartl $\mathrm{D}$ : Current concepts of hyperinflammation in chronic granulomatous disease. Clin Dev Immunol 2012;2012:252460.

35 Sica A, Mantovani A: Macrophage plasticity and polarization: in vivo veritas. J Clin Invest 2012;122:787-795.

36 Bystrom J, Evans I, Newson J, Stables M, Toor I, van Rooijen N, Crawford M, Colville-Nash P, Farrow S, Gilroy DW: Resolution-phase macrophages possess a unique inflammatory phenotype that is controlled by cAMP. Blood 2008;112:4117-4127.

37 Menten P, Wuyts A, Van Damme J: Macrophage inflammatory protein-1. Cytokine Growth Factor Rev 2002;13:455-481.

38 Balamayooran G, Batra S, Balamayooran T, Cai S, Jeyaseelan S: Monocyte chemoattractant protein 1 regulates pulmonary host defense via neutrophil recruitment during Escherichia coli infection. Infect Immun 2011;79: 2567-2577.

39 Fernandez-Boyanapalli RF, Frasch SC, McPhillips K, Vandivier RW, Harry BL, Riches DW, Henson PM, Bratton DL: Impaired apoptotic cell clearance in CGD due to altered macrophage programming is reversed by phosphatidylserine-dependent production of IL-4. Blood 2009; 113:2047-2055. 